\title{
Filosofía de la naturaleza y fenomenología material: cuando el búho de minerva deja de hacer vigilia en la noche y sueña
}

Philosophy of nature and material phenomenology: when minerva's owl stops making vigil in the night and dreams

Filosofia da natureza e da fenomenologia material: quando a coruja de minerva deixa de fazer vigia na noite e sonha

Juan Sebastián Ballén Rodríguez

\section{Resumen}

De considerar los fundamentos metafísicos de disciplinas humanistas que andan en boga hoy día como la bioética o la ecofilosofía, se tendría que considerar las discusiones de fondo generadas en la modernidad por la filosofía de la naturaleza y la fenomenología material. Efectivamente, la genealogía de los dioses, la teogonía, la antropología y los dilemas éticos implicados en una especulación en torno al concepto de naturaleza, fueron tópicos adelantados por el Schelling en su libro

Magister en Filosofía de la Pontificia Universidad Javeriana. Ha desarrollado estudios sobre fenomenologia, especialmente en torno a la obra de Michel Henry. Igualmente ha publicado artículos sobre estética, escritura, arte y sensibilidad. Correo electrónico: juansebastianballen@gmail.com 
Investigaciones filosóficas sobre la esencia de la libertad humana y los objetos con ella relacionados. Otra de las líneas abiertas en este trabajo es la planteada por Edmund Husserl, quien en Crisis propondrá la filosofía como una ciencia al servicio de los fines de la humanidad, más allá de la ciencia positiva y del psicologismo del s. XIX. El contraste de las apuestas filosóficas de Schelling y de Husserl pondrá de presente que dos actitudes filosóficas sobresalen en la tematización metafísica de la naturaleza: el relato de una ciencia en devenir llamada a evocar las grandes tradiciones mitológicas de oriente y occidente $o$ la fuerza prometeica de una filosofía llamada a velar por los intereses éticos de una ciencia empecinada en reducir el mundo de la vida a un hecho susceptible de determinación cuantificable (positivismo). La fenomenología material emergerá como una discusión planteada por Michel Henry al interior de los supuestos metodológicos de la fenomenología, particularmente en la aproximación de una noción de materia que, escéptica ante las posibilidades de que la filosofía asuma al papel de 'funcionaria de la humanidad', propondrá una narración cercana a la cromatizaciónimpresiva del mundo de la vida, escorzada por el encuentro entre subjetividad y materia. Una correspondencia que explora, entre otras cosas, ya no el devenir de la filosofía en la naturaleza o en la vocación normativa de una 'ciencia estricta', sino en el papel de la materia en la configuración de la vida anímica, el inconsciente y la corporeidad.

Palabras clave: Filosofía de la naturaleza, fenomenología, fenomenología material, J.W.F. Schelling, Edmund Husserl, Michel Henry.

\section{Abstract}

When considering the metaphysical foundations of humanistic disciplines that are in trend today as bioethics and ecophilosophy, would have to be considered the substantive discussion in modernity for the philosophy of nature and material phenomenology. Indeed, genealogy of the gods, theogony, anthropology and ethical dilemmas involved in a speculation around the concept of nature, were topics developed by Schelling in his book Philosophical investigations into the essence of human freedom and the objects related to it. Another of the lines 
opened in this work is presented by Edmund Husserl, who in Crisis would propose philosophy as a science at the service of the purpose of humanity, beyond positive science and psychologism of the nineteenth century. The contrast of the philosophical bets of Schelling and Husserl will show that two philosophical attitudes excel in the metaphysical theming of nature: the account of a becoming science called upon to evoke great eastern and western mythological traditions or the Promethean force called upon to look after the ethical interest of a science determined in reducing the life-world to an event susceptible of quantifiable determination (positivism). Material phenomenology will emerge as a discussion presented by Michel Henry within the methodological assumptions of phenomenology, particularly in the approximation of a notion of matter that, skeptical of the possibilities that philosophy assumes the role of "employee of humanity", will suggest a narrative close to the impressive chromate of the life-world, foreshortened by the encounter between subjectivity and matter. A correspondence that explores, among other things, not the becoming of philosophy in nature or the regulatory calling of a "strict science", but the role of matter in the shaping of mental life, the unconscious and corporeality.

Keywords: Philosophy of nature, phenomenology, material phenomenology, J.W.F. Schelling, Edmund Husserl, Michel Henry.

\section{Resumo}

De ter em conta os fundamentos metafísicos de disciplinas humanistas que andam em voga hoje em dia, como a bioética e a ecofilosofia, terse-ia considerar as discussões substantivas geradas na modernidade pela filosofia da natureza e a fenomenologia material. Na verdade, a genealogia dos deuses, a teogonia, a antropologia e os dilemas éticos envolvidos em uma especulação sobre o conceito de natureza, foram desenvolvidos por Schelling em seu livro Investigações filosóficas sobre a essência da liberdade humana e os objetos com ela relacionados. Outra das linhas abertas neste trabalho é a proposta por Edmund Husserl, o qual em Crise que propõe a filosofia como uma ciência para os fins da humanidade, além da ciência positiva e do psicologismo do s. XIX. O 
contraste das apostas filosóficas de Husserl e de Schelling vão colocar exaltadamente que duas atitudes filosóficas sobressaem na tematização metafísica da natureza: a narração de uma ciência chamada para evocar as grandes tradições mitológicas do oriente e do ocidente ou a força prometeica de uma filosofia chamada para velar dos interesses éticos de uma ciência ética teimosa de reduzir o mundo da vida a um fato suscetível de determinação quantificável (positivismo). A fenomenologia material emergira como um argumento exposto por Michel Henry ao interior dos pressupostos metodológicos da fenomenologia, particularmente na aproximação de uma noção da matéria que, cético das chances de que a filosofia assuma o papel de "funcionaria da humanidade", vai propor uma narrativa perto à cromatización impresiva do mundo da vida, encurtada pelo encontro entre a subjetividade e a matéria. Uma conformidade que explora, entre outras coisas, não mais o futuro da filosofia na natureza ou na vocação normativa de uma "ciência rigorosa", mas no papel da matéria na formação da vida anímica, do inconsciente e da corporalidade.

Palavras-chave: Filosofia da natureza, a fenomenologia, fenomenologia material, J.W.F. Schelling, Edmund Husserl, Michel Henry 
Así, corre la cortina: ¿Qué es lo que ves? -¡Más allá de tu angustia! ¿Estrellas? ¡Vaya, estrellas! ¿Y aún te atreves a hablar de sacrificios? ¿Del sacrificio de tu paz espiritual? ¿Del sacrificio de tu pureza? ¿Y no sonríes ante la 'magnitud' de esa pérdida inminente? ¿Qué nos importa a nosotros todas las pasiones, que nos importa toda la tristeza frente a esa tristeza única y apasionada con que desearíamos leer en las estrellas el misterio de su grandeza, de su inaccesibilidad, de su lejanía?

Esta pasión tenaz trata de persuadirnos de que solo con el secreto de estas estrellas descubriremos el secreto de nuestras almas.

Y hasta entonces...

Robert Mussil. Diarios 1899-1941.

\section{Introducción}

Pensar las posibilidades de la habitabilidad, la ecofilosofía y del medio ambiente en el escenario de la indagación filosófica implica hacer un rastreo de lo que se ha entendido por naturaleza, y de sus significados en los horizontes metafísico, teológico, moral, epistemológico y antropológico. El presente artículo se propone estudiar dicha categoría en tres órbitas teóricas de la filosofía. Primero, aborda la filosofía de la naturaleza que propuso el filósofo Alemán F. J. W. Schelling (17751854) en el siglo XVIII. Allí pretenderemos puntualizar el fenómeno del mal, inscrito en la problematización metafísica de la naturaleza que conecta con las indagaciones teológicas, antropológicas y cosmológicas. Nos interesa resaltar la conceptualización de la naturaleza como devenir del mal, que crea las condiciones de posibilidad de la libertad humana, y cuestiona las limitaciones de la metafísica de la subjetividad y de la ciencia que aflora en la modernidad. Desde este telón de fondo, incursionamos en una segunda órbita que retoma la problemática del mal, a partir del diagnóstico que hace la fenomenología de E. Husserl (1859-1938) alrededor del tema de la crisis de las ciencias europeas en el siglo XIX. En este 
segundo escenario se localiza la "metafísica del mal" en el ámbito epistemológico, y se desarrolla la tesis del último Husserl de que la filosofía es una ciencia volcada hacia la realización de las tareas infinitas, llamada a reivindicar la idea de humanidad y del devenir de la naturaleza en la historia. La tercera y última órbita retoma la noción de naturaleza que ha pensado la fenomenología de Michel Henry (19222002), radicalizando la categoría de materia, y abriendo así las posibilidades para retomar el problema del mal y de la oscuridad del mundo que describiera Schelling en los derroteros teóricos que hace de una fenomenología material. Esta se aparta de la idea de la filosofía como una teleología de la razón, esto es de entender su tarea como la orientadora de la humanidad para incursionar en el ámbito de las afectividades y de los sueños (vida anímica).

\section{La filosofía de la naturaleza en devenir y la agonía de la vida: el 'mal metafísico' del mundo}

Varias cuestiones se propone resolver una filosofía que se adjetiva bajo la gruesa palabra de naturaleza ${ }^{1}$. Una primera, si no la fundamental, tiene que ver con el origen de todas las cosas: a la filosofía de la naturaleza le compete el estudio sobre la génesis del mundo, del hombre y de Dios. Es, si se quiere, una disciplina que hace genealogía en un sentido muy particular: pues no pretende desentenderse de una explicación metafísica de las cosas. Una explicación que no hace propiamente una narración de las cosas, o de sus usos, sino de los conceptos que describen dichas cosas. Segundo, no le es ajena a esta filosofía, que fue practicada por los filósofos presocráticos, recurrir a la cosmogonía y a la teología. En este sentido, la filosofía de la naturaleza es una indagación sobre el origen del universo y de Dios. Tercero, la preocupación antropológica emerge en medio de los asuntos cosmológico y teológico. Como lo veremos en la filosofía de Schelling, la tematización antropológica estará concentrada en la

1 La filosofía de la naturaleza que aqui se esboza se amplia con la categoria de "actitud práctico universal", usada por Husserl para referirse a los antecedentes mítico-religiosos que dominaron en occidente antes de aparecer el concepto de ciencia. En toda comunidad precientifica la actitud mítico-religiosa se caracteriza por tematizar el mundo desde una totalidad. Son aspectos de esta actitud los siguientes: a) concepción del mundo desde una totalidad; b) la valoración espiritual del mundo concreto; c) la representación de seres suprahumanos; d) una mirada práctica de los asuntos humanos, según la cual estos se encuentran supeditados a las potencias divinas; e) la figura del sacerdote que administra los intereses religiosos de su colectividad con las fuerzas míticas; f) difusión del saber mítico de manera lingüistica; g) el sacerdote adopta la fama del sabio-mistico en donde su especulación está al servicio de los intereses prácticos y de conocimiento empírico-científico (cf. Husserl, Krisis, § 38). 
problemática sobre la libertad humana, vista dramáticamente como una capacidad de gobernar la existencia impulsiva en las polaridades morales y metafísicas del bien o el mal. El telón de fondo que escenifica este drama de la libertad es la categoría de naturaleza.

Como lo esgrime el filósofo alemán Rüdiger Safranski, Shelling en su Investigación sobre la esencia de la libertad humana, hace una reconstrucción del origen de las cosas desde los planos cosmológico y teológico (Safranski, 2010, p. 55). Para el filósofo del romanticismo alemán el devenir del mundo tiene su origen en dos movimientos: uno de dilatación, de explosión de una fuerza divina dirigida hacia el afuera y otro de contracción, de implosión, en el que la fuerza retorna a su origen. Este mismo movimiento pone de presente la relación entre el orden y el caos. Nuestro conocimiento, caracterizado como un estar despierto, hace vigilia de aquello que a nuestros ojos se pone de presente. Esto que vemos bajo la claridad de un mundo visible es el orden natural de las cosas, que es susceptible de formalización y clasificación. Sin embargo, cuando dejamos de conocer, esto es cuando se suspende el acto del entendimiento que formaliza la naturaleza en cosas, aplicado el conocimiento empírico-objetivo, advienen los presentimientos y el deseo de que detrás del orden, se oculta todo aquello que carece de regla. En esta insatisfacción que produce el deseo, se encuentra la impresión de que el orden, la luz del mundo, se origina de un caos primigenio, de una oscuridad en la que la claridad de la luz que golpea sobre el mundo se hace tal desde el fondo de las tinieblas. En este sentido, Schelling entiende que el conocimiento es un ansia que aspira a salir de la oscuridad para ingresar al reino de la claridad, con el sino de que si la claridad no se hunde en el subsuelo de la oscuridad, no alzará su condición diáfana:

Todo nacimiento es nacimiento desde la oscuridad a la luz; la semilla ha de ser hundida en la tierra y morir en las tinieblas a fin de que pueda alzarse una forma luminosa más hermosa y desarrollarse bajo los rayos del sol. El hombre se forma en el seno materno, y solo desde la oscuridad de lo que carece de entendimiento (del sentimiento y el ansia, maravillosa madre del conocimiento) nacen los pensamientos luminosos. Por lo tanto, así tenemos que imaginarnos el ansia originaria: dirigiéndose hacia al entendimiento, al que todavía no conoce, de la misma manera en que nosotros, en nuestra ansia, aspiramos hacia un bien desconocido y sin nombre, y moviéndose a la vez que presiente al modo de un mar ondulante y agitado, igual a la materia de Platón, 
buscando una ley oscura e incierta, incapaz de construir por sí misma algo duradero. (Schelling, 1989, p. 171)

Consideremos, según los términos mencionados, que la cosmología que se respira en la filosofía de la naturaleza de Schelling es la escenificación de un drama existencial en el que confluye incesantemente el movimiento del deseo, y no el de la razón, como génesis de la "vida consciente", que emerge de la oscuridad hacia la luz y viceversa.

Ahora bien, no sería acertado condenar dicha tesis como panteísta y determinista, si no damos cabida a la indagación que ofrece el filósofo sobre Dios. Schelling no deduce el drama de la libertad que subyace en la tensión entre el orden y el caos a partir del panteísmo o el determinismo, sino que lo relaciona con una teología agónica... una teología que, como se verá, es muy particular.

La relación entre los seres vivos y Dios no es del tipo mecánico, en la que el objeto creado -aquello que es producido por el gran productor (Dios)- son uno y lo mismo. Del mismo modo, la relación entre el todo divino y las partes que de él provienen no es de emanación, pues en esta situación ni lo que produce ni lo producido se distinguirían en esencia. La respuesta resulta alentadora: pues el antecedente (Dios) subsiste por sí mismo, mientras que su consecuente, los individuos son cuanto más se independizan del sí mismo que es Dios. Dicho de otro modo, somos ontológicamente diferentes porque en nada nos parecemos a Dios. Mientras que el gran productor permanece fiel a sí mismo, los individuos se han liberado en su radical inmanencia, y se muestran con esto diferentes, rebeldes al padre. $Y$ solamente en esta radical diferencia podemos entender la sustancia divina en su mismidad y a la orgánica, que es la nuestra, en su otredad (cf. Schelling, 1989, § 347/348, pp.137138). En consecuencia, nuestro vínculo con Dios no se produce en la mismidad, como supondrían el panteísmo, sino en la diferencia. Y, en esta medida, el drama de la libertad es el de la diferencia que batalla entre la esencia de Dios y la de los organismos vivos. El deseo, las ansias que gravitan entre la oscuridad y la luz, se entenderían como experiencias inmanentes de la diferencia y la agonía que subyace en la relación Dios-hombres.

Por otra parte, contra el determinismo, el filósofo alemán sostiene que esta doctrina considera que el vínculo entre Dios y los individuos es una relación cósica. En esta, 
Dios, este gran arquitecto sin alma y sin dinámica, ordena y dispone de los individuos como cosas inanimadas, sin vida. Lo que hace implausible el determinismo de las cosas es la voluntad. La voluntad es el acto potenciador; en este la naturaleza se transforma en sensación, inteligencia y finalmente en voluntad:

En suprema y última instancia no hay otro ser que querer. Querer es el ser originario y solo con este concuerdan todos los predicados del mismo: ausencia de fundamento, eternidad, independencia, respecto al tiempo, autoafirmación. (Schelling 1989, §350, p. 147).

Bajo el primado de la voluntad, el significado agónico de la libertad se muestra no bajo la abstracción del concepto moral (llámese deber), sino que se expresa a través del lenguaje siempre vital del querer. Pues se entenderá como una capacidad para el bien o para el mal. Tanto el bien como el mal hacen parte de esta filosofía agónica, que se propone expresar las fuerzas vitales que en movimiento reconocen la existencia del mal y del bien. Una posición idealista abstracta admitiría que la libertad es un concepto ajeno a la contingencia vital y dinámica que se desprenden de una noción natural de la voluntad. Sin embargo, el filósofo alemán define la voluntad como un principio originario, que produce un querer ilimitado el cual carece de fundamento, y puede engendrar tanto el bien como el mal. En esta medida, la segunda variable de esta "teología agónica" que subyace en la filosofía de la naturaleza esbozada por Schelling, entiende la libertad como un concepto real y vivo. La libertad es una realidad vital en el mundo, porque está inclinada hacia la realización de un impulso ciego y originario. El mal existe porque existe la libertad real del hombre (cf. Cardona Suárez, 2002, p. 9).

Este planteamiento es consecuente con el principio cosmológico según el cual la luz nace de la oscuridad. A juicio de Safranski, este principio explica el carácter dramático de la idea de evolución que subyace en la filosofía de la naturaleza planteada por Schelling. Efectivamente, hemos mostrado desde la noción de ansiedad, la mirada de un Dios que es fiel a sí mismo, y, sin embargo, su esencia participa en las criaturas que son finitas y diferentes, demostrándose así que la suma perfección se asoma hacia la imperfección. Por otra parte, el principio impulsivo de la voluntad es la otra cara de este Dios bueno, ya que es una potencia ilimitada, que arrastra todo, dejando al hombre en la capacidad real de elegir o por el bien o por el mal. De esa forma, la libertad es entendida en un sentido vital de lucha que oscila entre 
la claridad y la oscuridad, el bien y el mal. El drama de la libertad que se explicita en el poder ilimitado de este principio de la naturaleza que desata el impulso irrefrenable (voluntad), como el deseo de la libertad individual por conservar en su diferencia un querer, distante de la mismidad que representa la idea del Dios-uno, ponen de presente la nihilización del mal en un sentido ya no solamente moral sino metafísico (a este fenómeno lo acuña Heidegger como la metafísica del mal) y, de paso, explicita la complicidad entre el hombre y Dios, ya no a partir de la claridad pacífica del paraíso (la bienaventuranza), sino desde el fenómeno de la caída, en el advenimiento de la noche del mundo:

\begin{abstract}
Así pues la evolución de la naturaleza es un proceso dramático. Y este drama tiene que soportarse en el hombre, o sea, allí donde la naturaleza ha alcanzado la suprema conciencia. En él puede hacerse consciente y convertirse en acción libre el aspecto negativo de la potencia, lo carente de regla, lo caótico. Por eso en la libertad humana se da la opción de la nada, de la aniquilación, del caos. El hombre está metido en el ser, pero puede notar la tendencia a desgajarse de aquél, la tendencia a destruirlo. Y esto es el mal. Por medio de su libertad el hombre puede convertirse en cómplice del Dios inacabado. El abismo en Dios y el abismo del mal en la libertad humana están unidos entre sí. El hombre está unido con Dios, y, sin embargo, pertenece a su dificultosa herencia también el estar enlazado con el principio nocturno de este Dios, con su inacabamiento caótico. (Safranski, 2002, p. 57)
\end{abstract}

La bella metáfora que emplea Schelling para referirse a la diferencia entre el ser como existencia y como fundamento de existencia, nos permitirá dimensionar la complicidad entre el hombre y Dios en las dos vertientes análogas: tanto en la caída como en la bienaventuranza. La clave de esta analogía entre el principio oscuro y el principio de luz está en el sentido de la categoría de naturaleza. La razón es que es la naturaleza actuando sobre Dios lo que constituye el fundamento de la existencia. La metáfora expresa que la fuerza de gravedad precede a la luz como el fundamento oscuro que huye en la noche y la luz como aquello que es existente y que se levanta en la aurora. La fuerza de gravedad, que es la inercia de las cosas dirigidas hacia un centro oscuro, es la misma naturaleza actuando sobre Dios, de ahí que la oscuridad devenga en luz. La metáfora nos acerca a una idea de naturaleza entendida no como el precedente oscuro, principio indeterminado y determinante de todo lo demás, sino como devenir. Por lo tanto, el devenir de las cosas naturales no reproduce la esencia 
de Dios, sino que, en su movimiento, se liberan de su creador. Queda así respetada la esencia de Dios que es el ser que se guarda a sí mismo, y el ser de todo lo existente que es aquello diferente de Dios, rebeldía y otredad. Las cosas naturales participan de la esencia de Dios no en aquello que lo caracteriza como propio, sino en su diferencia. Y esta diferencia es para Schelling el ansia. El ansia es el deseo de la unidad perdida. Es la nostalgia de la totalidad que expresa el ansia o el deseo de conocimiento, que es el mismo anhelo de reconciliación. Es un sentimiento del desgarramiento, pero que presiente la claridad del entendimiento. Pertenece al mundo del preconocimiento, que se asienta primordialmente en el reino de la voluntad.

El fenómeno antropológico, a partir de la teoría de la voluntad, adquiere un matiz especial. La voluntad de las criaturas se encuentra alejada del fundamento. La no participación de la esencia divina en la inercia en la que cae la voluntad particular da razón del mal como un fenómeno de distanciamiento, que nace de un querer que se ha marginado de la voluntad central y ordenadora. La voluntad del hombre surge como una separación respecto de la mismidad, que reúne el principio de la luz. La oscuridad adviene como manifestación de un querer singular, alejado del centro espiritual representado por Dios. Mientras persiste el amor de las criaturas hacia Dios, dominará el principio de la luz; cuando la relación resulta repulsiva, sembrada la discordia, decimos que domina la voluntad particular. La enfermedad es un fenómeno en el que se muestra el alejamiento de la voluntad particular del centro. La salud se entenderá como el regreso de la voluntad particular hacia el centro donde impera la plenitud y la armonía.

Quisiéramos resaltar, finalmente, que la opción metodológica propuesta por Schelling para la filosofía de la naturaleza es la grilla entre el idealismo y el realismo: "[e]l idealismo es el alma de la filosofía; el realismo su cuerpo. Solo la reunión de ambos constituye un todo vivo” (Schelling, 1989, \$356, p. 159). A partir de estos dos ámbitos que se reúnen en uno solo, la tarea de la filosofía de la naturaleza consistirá en mostrar que cada proceso de la vida se aproxima a la esencia de la naturaleza (cf. Schelling, 1989, \$362, pp. 173-175). El filósofo alemán establece que en el hombre habitan dos principios constitutivos: el concupiscible, en el que la voluntad se particulariza envolviéndose en el caos y la oscuridad de las afecciones y los sentimientos, y el del entendimiento, que aspira hacia la luz y primordialmente se orienta en dirección hacia el centro anhelado: Dios. En este sentido, la filosofía de la naturaleza asumirá la tarea 
de describir el proceso en que la voluntad particular abandona su propio egoísmo que enferma y produce el mal, para dirigirse hacia el centro armónico de la divinidad.

Pretendemos ver en esta propuesta metodológica una antesala para lo que formulará el siglo XIX con la fenomenología como una alternativa metodológica y teórica ante la crisis histórica que reconstruye la narración del devenir de la naturaleza en el horizonte de la historia y particularmente de la idea de filosofía, formulada por el último Husserl en su dimensión salvífica y teleológica.

\section{Del devenir en la naturaleza al devenir en la historia: la incursión de la fenomenología en la época de la crisis de las ciencias europeas y la fuerza proteica de la filosofía}

Todo indica que la batalla entre la oscuridad y la luz está ganada por la inercia del principio de la gravitación universal, que siendo la oscuridad en su origen, para luego devenir en aurora, aparecerá como la anticipación del día. La naturaleza es entonces un poderoso devenir, un llegar a ser. En el tránsito que supone este devenir, la conciencia adviene como ansia y deseo, que es igualmente la anticipación del alumbramiento. El devenir de la naturaleza actúa en la conciencia inacabada, que se muestra en su aspecto volente como ansia de infinitud. Ahora bien, ¿cómo incursiona la fenomenología en esta filosofía de la naturaleza en devenir? Nos aventuramos a considerar la tesis de que la fenomenología, en su aspecto metodológico e histórico, escenifica los síntomas de una hermenéutica de la metafísica del mal, que planteara Schelling en La esencia de la libertad humana en el siglo XVIII. Cuando hablamos de hermenéutica del mal, nos referimos concretamente a la no realización del proyecto de la razón moderna, a saber el conocimiento objetivo del mundo se rinde ante el primado de la voluntad, que es el querer ilimitado en su aspecto moral y metafísico, ansia y deseo en su dimensión gnoseológica y cosmológica. Del mismo modo, la fenomenología asume la tensión epistémica que produce, por un lado, el psicologismo positivista $y$, por el otro, el idealismo abstracto; en resumen, considera que la ciencia positiva ha guillotinado la fuerza del espíritu en la comprensión fenomenológica de la naturaleza, y esto ha producido la crisis de las ciencias en el siglo XIX. Así como el ansia, que es un querer ilimitado tanto de conocimiento como de acción, y que vive atravesada del desgarro y de la impotencia, para Husserl el signo de los tiempos en 
los que impera la ciencia positiva y el saber instrumentalizado que provee la técnica reconstruye la historia presente de la crisis de la ciencia europea. Si para Schelling la comprensión de la naturaleza en devenir requiere de la simbiosis metodológica entre el idealismo y el realismo, para Husserl es en la teleología como se recuperará el saber añorado de una "naturaleza humanizada"2.

En la conferencia La filosofía en la crisis de la humanidad europea, Husserl parte del supuesto de que es necesario inspirar la historia de la filosofía europea desde la teleología, de tal manera que sea al mismo tiempo una recuperación acerca del significado de la humanidad, que ha sido silenciada por obra de la crisis de las ciencias europeas. Un significado que emerge en el contacto que hace la filosofía con la cultura. Empero, la filosofía ha retrocedido en su relación de sentido con la cultura, acentuándose el abismo entre estas esferas, en la diferencia sintomática desatada en el deslinde metodológico de la "medicina científico natural" y la "medicina naturalista". Esta diferencia muestra dos vías posibles de adquirir un conocimiento sobre la vida. Una que parte de la empirie y tradición popular y otra que parte de los conocimientos puramente teóricos. La crisis tiene su génesis en una división interna creada por la metodología de las ciencias objetivas. Pero esta brecha no solamente se comprende como una fractura en la lógica interna de la ciencia médica, pues justamente el cambio de orientación distancia el saber médico de su historia popular, esto es de la comprensión de que la vida personal de los hombres es un vivir en comunidad. La fisiología le ha ganado terreno al saber tradicional de la medicina, la cual históricamente emerge de la cultural. En el contexto cultural, la vida no es un objeto de cuantificación teórica, sino una tendencia hacia los fines y valores relativos de una comunidad. La crisis ha sembrado la enfermedad bajo el primado de la explicación científico-natural de las cosas. La Europa de la crisis de las ciencias europeas es una sociedad culturalmente enferma, que involuciona

2 Quisiéramos acentuar el papel de consideración que juega la cultura en la reconstrucción de un saber perdido en el panorama de la crisis de las ciencias europeas, como una continuación del proyecto anticipado por Schelling de hacer de la filosofia de la naturaleza el verdadero fundamento de la metafísica moderna. Se debe entender con esto que en esta filosofía se piensa que los orígenes de un saber real y vivo se encuentran en la mitología y la religión de los pueblos. De otra forma, no podriamos reconocer que el primado del principio oscuro en pugna contra el principio de luz menta a la creación del mundo, que, según la historia biblica, parte del caos inicial (Safranski, 2002, p. 219). Husserl, a su vez, reconoce que el olvido implicado en la crisis de las ciencias europeas tiene que ver con el desconocimiento que hace la ciencia positiva de la historia de los dioses y de los hombres. Con ello, no se disipa la tesis según la cual la teleología se convertiria en la coronación de la historia de la razón desde los griegos, imponiéndose victoriosa sobre las ruinas producidas por la ciencia moderna. 
históricamente respecto de modelos culturales en los que persiste el saber tradicional. Paradójicamente, Husserl señala que en medio de este panorama, dominado por los conocimientos teóricos puros, no se ha descubierto la medicina científica que diagnostique y supere la enfermedad de las naciones europeas. ¿Será la filosofía o mejor la fenomenología trascendental el antídoto ante la crisis?

El caso de la medicina, que bien explicaría su precaria situación en la actualidad, pone de presente que las leyes formuladas por las ciencias objetivas pierden de vista el significado vital de la experiencia e incorporan un sentido mecánico, objetivo y positivo de reducción de lo sensible a la abstracción matemática. Como resultado del creciente dominio de la ciencia natural matemática sobre el mundo empírico, se origina la revolución en el saber que permitió el control de la naturaleza a través del uso de la técnica.

Ahora bien, las ciencias del espíritu han avanzado en un sentido contrario al de las ciencias objetivas. A juico de Husserl el campo de estudios de estas ciencias es la vida psíquica, particularmente la corporeidad. Las ciencias humanas se ocuparían del pensamiento que se ha materializado en el cuerpo individual y colectivo. El presupuesto epistémico que caracteriza a los saberes humanísticos afirma que la espiritualidad está fundada en la corporeidad. El cuerpo, para la ciencia natural, es un hecho o res extensa manipulable con el cálculo de la cuantificación. La noción de cuerpo se ha objetivado, y esto ha ido en detrimento de una comprensión vital-espiritual de este.

Al igual que la noción de cuerpo, la de naturaleza ha perdido su sentido teleológico, esto es histórico y cultural. Para Husserl, la tarea de la filosofía futura consistirá retomar el concepto de naturaleza explorado por la cultura griega. La naturaleza es entendida desde la perspectiva de los griegos como "[...] el mundo circundante de la realidad natural [...]" El mundo inspirado en la concepción griega no se bate entre la subjetividad o la objetividad, sino se concibe a partir de una escenificación reflexiva del mundo. El mundo de la realidad natural de los griegos es el de los dioses y de los demonios ${ }^{3}$.

3 Esta postura de la naturaleza que vive animada de una tradición que le entiende desde una perspectiva mitológica, nos permite enlazar con la lectura Schelling, que la entiende desde un punto de vista metafísico, en el que la polaridad de las fuerzas ilimitadas se despliegan en la lucha, dramatizando el sentido de la existencia del hombre. 
El mundo circundante tiene valor para la vida espiritual: "[n]uestro mundo circundante es una formación espiritual en nosotros y en nuestra vida histórica” (Husserl, 1981, p. 142). Lo natural, para los griegos, como aquello que circunda el mundo, desborda los límites de la pura subjetividad, e inserta al hombre en el devenir del mundo vital. La teleología daría respuesta a la historia de la humanidad en devenir, porque no responde a la lógica del movimiento biológico-material que domina en la idea de evolución. La teleología acentúa en el valor histórico de la diferencia. La estructura de las ciencias naturales no pueden decir nada acerca de la esencia espiritual de los pueblos en su diferencia, pues "[n]o existe esencialmente una zoología de los pueblos" (Husserl, 2008 p. 142). Mientras que en la lógica de la evolución se establecen etapas finitas y acabadas de la historia del hombre, en la entelequia fenomenológica de los pueblos, la historia se condensa en unidades espirituales, que no han llegado a su consumación de una forma acabada y definitiva: "[1]a humanidad psíquica nunca ha sido acabada y nunca lo será y nunca puede repetirse" (Husserl p. 142). Por lo tanto, la entelequia espiritual de la humanidad en su unidad no tiene un término final, sino un movimiento infinito. La historia de la humanidad es una historia en devenir.

Sin embargo, Husserl entiende que la filosofía está llamada a realizar las tareas infinitas que ha postergado el proyecto científico-técnico de la filosofía moderna. En otras palabras, la teleología que da cuenta de la historia en devenir y que ha diagnosticado el mal espiritual de una cultura a partir de sus formas de producir conocimiento (psicologismo y positivismo), ve en la filosofía la fuerza proteica en la que se condensa la esencia espiritual de Europa (cf. Banfi, 1968, p. 361). La filosofía es entendida por el último Husserl como una praxis histórica de la razón que se remonta desde la cultura griega, que tiende hacia la conducción de una idea normativa de humanidad, esto es seguida por unos valores absolutos, que garantizan la libertad del pensamiento: en la que la conciencia teórica se libera de los intereses particulares y guía a una cultura hacia la máxima realización de la idea de humanidad. La fenomenología se convierte así en la propuesta filosófica que orientaría a una cultura hacia la realización de las tareas infinitas. Efectivamente, la máxima conquista que ha ofrecido la filosofía contra el dogmatismo, el realismo y el escepticismo ha sido el descubrimiento de la autoconciencia. Esta conciencia de sí pone de presente que el sujeto trascendental se encuentra más allá de la mera condición natural. La conciencia intencional, que es la que está dirigida hacia las cosas mismas, desancla a la razón de su dimensión empírica y pasiva que dominaba en la actitud natural, para encaminarla hacia la toma 
de posición, la crítica y la problematización del mundo. Este segundo momento del método fenomenológico se comprende como la suspensión del juicio, la puesta entre paréntesis de los hechos reales (epojé), para resignificarlos en una actitud filosófica de conocimiento (reducción eidética).

Es así como la teleología de la historia se realiza en el movimiento teleológico de la razón. Para Antonio Banfi, filósofo italiano y discípulo de Husserl, la idea de razón que defiende el fundador de la fenomenología con su propuesta de que en la filosofía, el hombre encontrará su auténtica esencia universal como salida ante la crisis, responde a una concepción proteica de la razón:

[...] la razón es el fuego donde se concentra toda la vida, toda la obra, toda la fe de los hombres y es en ella únicamente que los hombres encuentran su certeza porque ella es la fuente de una renovación perpetua de la vida, de la obra y de la fe. (Banfi, 1968, p. 366)

La fenomenología trascendental resume el devenir de la teleología de la razón, porque explica que la determinación filosófica del mundo exige abandonar los prejuicios, las creencias y las opiniones que se han incubado en el estado de la actitud natural. La reducción trascendental plantea de golpe que el mundo uno que se muestra en la actitud natural tiene que ser resemantizado a partir de una segunda actitud, la filosófica o reflexiva, la cual tomaría distancia del estado de normalización imperante de la actitud natural. La fenomenología estudiaría así la serie de intencionalidades que otorgan sentido eidético al mundo de la vida. La conciencia intencional continuaría en este sentido el proyecto de la filosofía moderna de establecer las condiciones de posibilidad de las representaciones del mundo, dejando abierta la pregunta por la constitución somática y material de la subjetividad. Así las cosas la fenomenología intencional o trascendental, si bien asumiría el proyecto teleológico de la razón, silenciaría el devenir de la naturaleza, que, como lo hemos argumentado desde la filosofía de la naturaleza de Schelling, no muestra precisamente la victoria de la razón sobre la sinrazón, sino, más bien, la impotencia de la ciencia al momento de explicar el mal en el mundo en relación con la libertad humana. En esta medida, haremos un giro más audaz al interior de la fenomenología, para reconocer que la idea de naturaleza como el devenir de la luz en la oscuridad cobra relevancia en la fenomenología material de Michel Henry. Este último giro nos permitirá conectar finalmente la idea de naturaleza dentro de un campo que explora las batallas entre los principios del bien y el mal, desde el lado oscuro de 
la conciencia. Una nueva filosofía de la naturaleza se plantea desde el psicoanálisis. La metáfora del búho de minerva tomando vuelo tan pronto el ocaso llega es una imagen que bien describe la situación de la fenomenología intencional en su firme actitud de redimir a la humanidad en la noche del mundo, persistiendo en la vigilia y en la posibilidad real de que la filosofía asuma el papel de guía de la humanidad. Sin embargo, consideramos que llegada la noche exige que la filosofía radicalice la manera de mirar el mundo, ya no haciendo valer la claridad sobre la oscuridad, sino reconociendo que la habitabilidad del mundo se constituye en la materialidad. Esta materia se halla en tinieblas, y pigmenta la conciencia de un mundo onírico y de ilusión.

\section{El devenir de la naturaleza en la inercia oscura de la materia: cuando el búho de minerva se descubre en la vida onírica}

Henry señala que en la fenomenología de Husserl se distingue claramente entre los contenidos materiales de la percepción y las impresiones subjetivas. Desde la perspectiva trascendental, la cual establece las condiciones de posibilidad de objetivación de la percepción sensible, la intencionalidad vendría a constituir objetivamente a las impresiones materiales que registran los sentidos. Empero, los elementos sensibles, esto es los registros materiales que capta la percepción en la actitud natural se encuentran desprovistos de intencionalidad. En la perspectiva de Husserl, se identifica un doble movimiento al momento de abordar el contenido hylético de la percepción sensible, pues, por un lado, la materia hace parte de la realidad misma que constituye el ser de lo que percibimos, y, por el otro, este mismo contenido material carece de cualquier sentido intencional. De esta manera, la fenomenología se divide metodológicamente en dos orientaciones. En una queda establecido que el contenido material de la percepción sensible constituye a la conciencia intencional que se encuentra afectada por el mundo. En otra, la perspectiva intencional provee de sentido y dirección a la materia que perciben los sentidos. La materia en sí misma no puede ser intencionalidad. Husserl reconoce en el $\$ 97$ de Ideas que una vivencia es un compuesto entre los "momentos hyléticos" y las "aprehensiones que los animan" (Henry, 2009, p. 43)

Sin embargo, la cuestión sobre la génesis de toda vivencia queda sin respuesta. Henry declara que para llegar a la subjetividad en un sentido absoluto se tiene que sobreponer la fenomenología ante la ambigüedad que genera el contenido hylético de las percepciones sensibles y la conciencia intencional. A partir de la diferencia 
metodológica entre hyle (materia) y morphe (forma intencional), se está poniendo en juego el sentido del archifenómeno, o fundamento sobre el cual emerge originariamente la conciencia objetiva. En la primera tesis que esboza Henry para sostener teóricamente una fenomenología material, se afirma lo siguiente:

A título de anotación preliminar, digamos aquí simplemente que la fenomenología material tal como la concibo resulta de esta reducción radical de toda trascendencia que libera la esencia de lo sub-yacente a la sub-jetividad en calidad de su contenido hylético o impresional. (Henry, 2009, p. 44)

En otras palabras, la reducción del mundo no declara que el contenido material de este ejercicio se encuentra en el movimiento intencional de la conciencia, en el que se presenta una cierta modalidad "trascendental" en la comprensión del fenómeno (hacemos referencia a las formas que integran las actividades trascendentales de la conciencia, como el recuerdo, la imagen, la idea, la memoria, etc.). Por el contrario, el contenido impreso en la piel misma (con ello hacemos referencia a las modalidades inmanentes del pathos de la vida como la impresión, el afecto, el dolor, el gozo, etc.) viene a ser el reducto fenomenológico que da noticia de una subjetividad, que antes de modular la representación del mundo, lo desea, sufre y lo padece. La evidencia del ego para la fenomenología material no viene dada mediante las autoafirmaciones de la conciencia que, finalmente, constituye un mundo a la medida de las diversas aproximaciones intencionales al mundo de la vida, sino de las tonalidades, las impresiones, los registros sonoros, los ecos, los movimientos, en fin, la materia que termina por configurar a la misma conciencia intencional. Esta tesis conduce a la fenomenología material a repensar una reducción trascendental más radical que la practicada por Descartes, pues si bien es un ejercicio que pone en suspenso el mundo, no concluye finalmente que hay una cosa que piensa, sino, más bien, un contenido material de la cosa que constituye a la vivencia. El cogito cartesiano es trastocado en su comienzo, pues el resultado de la actividad de la razón no es el sí mismo de la entidad pensante (hombre) sino aquello otro, diferente, que es materia y que permanece impreso en la piel. En esta medida, el origen del posicionamiento del ego en el mundo no se produce en la articulación o correlación entre la materia y la forma intencional, lo cual, da lugar a la aparición del pensamiento, y, en consecuencia, del el autoposicionamiento del ego cogito. Es en el silencio de la carne que se afecta y padece en el que se manifiesta la génesis de la subjetividad. 
Sin embargo, aquello que permanece en silencio ante la indecisión de si primero se dio el contenido hylético o la morphé de la conciencia intencional, es justamente el archi-fenómeno. La materia es el caldo de cultivo de una subjetividad afectada por el mundo. La definición del concepto de materia, se aproxima, en un sentido radical, a la afectación somática que constituye la vivencia subjetiva:

El término materia designa primordialmente la esencia de la impresión o de lo originalmente y en sí idéntico a ella, la sensación. La materia es precisamente la materia de la que está hecha la impresión o de lo originalmente y en sí idéntico a ella, la sensación. [...] Hablar de 'datos sensibles', de 'momentos hyléticos de la vivencia', no supone otra cosa que atenerse al 'color sensible' (Empfindungsfarbe), a la pura impresión sonora reducida a sí misma, a lo que ella es en sí (la reducción es justamente la vuelta a las cosas mismas) y, de manera similar, al puro dolor, al gozo puro, a todas esas vivencias definidas por su carácter impresional así como delimitadas por él: una vez más no son otra cosa y, particularmente, en cuanto que pertenecen a la hylé, son por principio no intencionales. (Henry, 2009 p. 46)

Henry se propone liberar a la materia de su relación con la forma intencional. Para ello, sugiere que la relación entre materia e impresión no sea entendida a la manera de un contenido objetivo, un dato sensible, sino que, más bien, sea leída como una vivencia simbiótica entre el fenómeno (impresión) y su mostración (la impresionalidad). En la teoría de Husserl, la intencionalidad convierte a la materia en el objeto de los posibles significados que se erijan para las vivencias. La materia no constituye como tal una vivencia sino es en relación a las "formaciones intencionales". Esto deja a la materia en desventaja con relación a la intencionalidad, pues esta última termina por limpiarla acortando su alcance ${ }^{4}$ (escorzada), su riqueza fenomenológica; en este sentido, la materia cumple su función de informar a la conciencia:

La materia no es la materia de la impresión, lo impresional y la impresionalidad como tales; es la materia del acto que la informa, una materia para esta forma. El darse de esta materia tampoco le pertenece: no es la materia misma la que da, la que se da ella misma, en virtud de lo que ella es, por su propio carácter impresional. (Henry, 2009, p. 47)

4 Escorzar es el verbo que emplea el traductor para referirse a la delimitación que hace la conciencia intencional. 
Entre la conciencia intencional y la materia se establece una diferencia: el del mundo de representación y el de la impresión. Sería un engaño considerar que estos dos mundos en la fenomenología se encuentran distantes. Sabemos que la materia subordina su contenido a la intencionalidad, pero el cuestionamiento del filósofo francés señala que no es la tonalidad de la materia misma la que hace parte de manera plena en la donación de sentido que aflora en la intencionalidad. Más allá de señalar dos momentos de la correlación que configuran las vivencias, lo que queda como un interrogante es justamente la unidad de la subjetividad (cf. Henry, 2009, p. 48).

Una cosa más. Los datos sensibles, la sensibilidad como tal, permanecen en el mundo de las percepciones primitivas de la conciencia. A juicio de Henry, el sentido fenomenológico que hace Husserl de la materia se explica a partir de los términos: estados afectivos, impulsos sensibles, afectividad y pulsación. Todas estas modalidades que constituyen el material de la intencionalidad se convierten en "[...] datos sensibles de la percepción" (Henry, 2009, p. 50).

¿Qué se quiere decir con la tesis de que la materia misma constituye a la impresión? Esta hipótesis de trabajo que plantea Henry propone identificar el elemento impresional en su estado puro (cf. Henry, 2009, p. 51). Evidentemente, esta es una investigación que desde el punto de vista de la fenomenología husserliana, en un principio, se encuentra en ciernes, en el sentido de que todo contenido hylético se subsume bajo la conciencia intencional:

Sin duda alguna, el hecho de que los datos impresionales se pongan en evidencia a partir del fenómeno de la percepción y por su mediación, el hecho de que se designen como 'escorzos', es decir, escorzos de las cosas precisamente, no es por azar: para la fenomenología histórica se trata de evitar un obstáculo desgraciadamente inevitable. En el caso preciso de la percepción, a la impresión le corresponde un correlato noemático. ¿Pero qué es de la impresión, nos preguntamos, cuando ya no se produce correlato alguno de este género? Ahora bien, esto es lo que sucede en el caso del sentimiento, del conjunto de las vivencias de la esfera afectiva, pulsional y volitiva. Resulta imposible definir un miedo, un placer, un deseo, una pura cabezonería de otro modo que por su modo carácter afectivo. [...] El golpe de mano de la fenomenología de Husserliana, tanto más brutal por inconsciente, radica en interpretar siempre y en todo momento el poder de revelación de lo impresional y afectivo como tal, de 'esta función en contraste con el carácter informante', es decir, de suyo 
excluyente de toda intencionalidad, como constituido precisamente por esta. Tan pronto como la afectividad es considerada desde el punto de vista fenomenológico como revelante, no es en sí misma, por su afectividad, como lleva a cabo la obra de la revelación, sino en tanto en cuanto participa de la esencia general de la conciencia. En cuanto que es intencional. (Henry, 2009, pp. 52-53)

La fenomenología material no es la misma fenomenología intencional. De hecho, Henry considera que en la teoría de Husserl la perspectiva trascendental (la indagación epistemológica sobre las condiciones de posibilidad del conocimiento) convierte al contenido hylético en el referente sobre el cual se proyecta la conciencia intencional (como reza el dictum de la fenomenología husserliana toda conciencia es conciencia de algo). Sin embargo, la pregunta sobre la materia originaria permanece en el misterio. Hay un comienzo desconocido del cual emerge un contenido vivenciado y conocido. Y en este sentido, para Henry, lo trascendente no se encuentra solamente en el mundo conocido (intencional) sino en el desconocido, que si bien es originariamente ciego, es, empero, el que posee la luz y en donde la materia constituye toda mostración impresional. Lo trascendental no es el reducto de la intencional (la esencia), sino el contenido de la impresión en su estado puro.

Todo lo que se nos da está constituido [...]. Pero lo constituido es de suyo necesaria y primordialmente algo no constituido. Todo es trascendente pero lo trascendente es de suyo primordialmente no trascendente. [...]. La primera donación es misteriosa, es la Empfindung. Se trata en este caso de una cierta donación y un cierto algo dado, de tal modo que, aquí, lo dado es el modo de donación mismo: la afectividad es una y de manera idéntica tanto el modo de donación de la impresión como su contenido impresional -lo trascendental en un sentido radical y autónomo-. (Henry p. 57)

No obstante, en el $\$ 86$ de Ideas $I$, hay indicios teóricos para constituir a la fenomenología material en una disciplina independiente. La primera condición que establece Henry para esta fenomenología parte del presupuesto de que la materia ya no está subordinada a la intencionalidad, sino que entra directamente a configurar el sentido de la donación de las cosas, esto es hace énfasis en un análisis fenomenológico en el que se descubre que los fenómenos se muestran en el cómo de la donación: “[...] los objetos de la percepción trascendente solo se nos dan a través de sus apariciones 
sensibles, de tal modo que estos datos desempeñan propiamente un papel de fundamento para la donación de todo objeto percibido" (Henry, 2009, p. 58).

De esta manera se invierten los papeles, pues la hyle ya no es el contenido ciego que informa a la intencionalidad. Dicho de otro modo, la materia no es el objeto de la modulación de la conciencia, sino "[...] las materias impresionales, según el juego de su presentación, las que dictan a la nóesis las modalidades de su propio cumplimiento" (Henry, 2009, p. 58).

Una cuestión que no puede quedar en mora para la fenomenología material es sobre la manera en que están dados los datos que constituyen a la vivencia. En otras palabras, se trata de averiguar la cuestión sobre lo que antecede a la materia y que es, de hecho, su condición de posibilidad (¿Dios, el ser, o el inconsciente?). En principio, este origen no se encuentra en la conciencia intencional. De hecho, si el sentido de la intencionalidad en Ideas I alude a la visibilización de las cosas, entonces, tal fenomenología permanece atrapada en los laberintos de la racionalidad (cf. Henry, 2009, p. 60). Lo que se sale de la intencionalidad (continúa Henry los comentarios a Ideas I) son flujos de sensaciones, complejos psíquicos, complejos de contenido -que existen pero que carecen de significado, todos ellos, procesos que hacen parte del flujo de las vivencias o los torrentes de conciencia-. Estos contenidos materiales percibidos por la impresión, pero escorzados, delimitados por la conciencia, permanecen mudos, silenciados por una conciencia intencional que no sabe cómo clasificarlos. Henry acoge la caracterización husserliana que señala que dichos contenidos vagan libremente, pues generan múltiples aprehensiones. El contenido material, los flujos de impresiones son ilimitados y en ello radica su libertad. La pregunta que indaga sobre el origen de las donaciones hyleticas tiene dos salidas: una, reconocer la autodonación de la materia, pues su carácter libre explica esta misma capacidad autónoma para generar significados distinguiendo aquí mismo el caos y la multiplicidad que explican su génesis, o, por otro lado, retornado a la fenomenología formal-clásica, se declara que el contenido material depende de la intencionalidad que ordena la multiplicidad de los flujos de sensaciones (Henry, 2009, p. 61).

Una tercera salida baraja el filósofo francés. Esta tiene que ver con el tiempo. Los oscuros parajes que experimenta la conciencia en relación con el tiempo determinan el origen de los contenidos hyléticos. El tiempo sería la clave para entender el problema sobre el origen de la materia: 
La constitución del tiempo mismo, del tiempo fenomenológico inmanente, es la constitución original, que constituye todos los elementos subjetivos a su vez constituyentes del mundo y del tiempo que le pertenecen: ella es la archi-constitución que lleva a cabo la archi-donación. Lo que quiere decir: La archi-donación es una archi-constitución, es la archi-constitución del tiempo. La temporalidad es el archi-ek-stasis que constituye la archi-fenomenicidad. La archi-donación, como archi-constitución, como archi-éxtasis del tiempo, atañe precisamente a la impresión, a la hyle, pues ella es su propia donación, su auto-donación a sí misma de tal manera que esta donación no es una auto-donación: aquello que da no es la Impresión misma sino la Archi-intencionalidad. (Henry, 2009, p. 62)

A pesar de que en el presente estudio el tiempo no será la categoría sobre la cual se fundamente ontológicamente la impresión, pues como lo muestra indistintamente en el análisis que dedica a las Lecciones de Husserl, permanece subordinada a la conciencia, conviene señalar aquellos puntos críticos que el filósofo francés resalta como obstáculos metodológicos para la misma propuesta de una fenomenología material.

Relacionar la impresionaliad con la conciencia de la temporalidad es una tesis que Henry cuestiona de las Lecciones de 1905, en las que Husserl aborda la relación entre la fenomenología y el tiempo. Para Henry, este texto es uno de los más bellos de la fenomenología, entre otras cosas porque en él aflora la inaudita afirmación de que “[...] la Impresión es aquello que da principio al principio que hace ver toda cosa, aquello que revela originalmente la intencionalidad a sí misma” (Henry, 2009, p. 65). Lo que llama la atención a Henry de dichas lecciones es justamente el papel que le asigna Husserl a la impresión, la cual deja de ser aquella actividad informadora de la intencionalidad, para ser entendida, ahora, como la matriz desde la cual brota la donación de sentido fenomenológico:

En efecto, la tesis según la cual la conciencia es impresional tiene y debe tener un alcance absolutamente general, significando no solo que siempre y en todo lugar -sin que, por otra parte, se sepa por qué- la conciencia se encuentra afectada impresionalmente, sino que la impresión, mejor dicho, la impresionalidad constituye la conciencia misma, a saber, la fenomenicidad pura como tal, la materia y la sustancia fenomenológica de la que está hecha y, así, la fenomenicidad original de todos los fenómenos. (Henry, 2009, pp. 65-66) 
La reducción que plantea Husserl en sus Lecciones no se limita a ser una descripción pura del dato material que retiene la impresión. No encuentra Henry que en la impresión husserliana se identifique la autoafección radical del contenido hylético; más bien, Husserl entiende que la impresión y el dato material se experimentan bajo la conciencia del presente, entendida como la "conciencia originaria", que hace referencia a la "conciencia interna del tiempo". En esta última, se hace presente la experiencia de la temporalidad bajo una impresión primitiva o "sentir originario" (Henry, 2009, p. 68). La impresión originaria se reduce a la conciencia del tiempo, esto es a la misma experiencia de la temporalidad que en algún momento criticó van Peursen $^{5}$ en los famosos Cahiers de Royaumont (van Peursen, 1968). Cuestiona el filósofo francés del sentido que le otorga Husserl en sus lecciones a la impresión, su marcada inclinación hacia una conciencia del presente, a una intencionalidad, que hace ver el dato de la impresión. La cuestión sobre la "carne afectiva" de la impresión misma permanece silenciada por la conciencia originaria del tiempo presente (Henry, 2009, p. 68). Al ser entendida la impresión originaria como conciencia del tiempo presente, esta actividad pierde el contenido ontológico que provee la "realidad real" (Henry, 2009, p. 69). Al contrario, para nuestro filósofo, la experiencia del tiempo en su presente no es la causa que resume el contenido de la impresión misma, sino más bien su efecto, pues tomando por caso la experiencia del dolor, no hay ningún manual de instrucción o forma intencional que describa en su viva experiencia, las diversas patologías carnales y los sentimientos implicados en el dolor mismo, en tanto que impresión somática primitiva y originaria. La conciencia originaria del tiempo no se encuentra en la conciencia del tiempo presente, sino en la impresionalidad y la afectividad misma (cf. Henry, 2009, p. 69). El análisis que plantea Henry de la manera como en las Lecciones de Husserl se aborda la impresión lo lleva a concluir que dicha actividad permanece atrapada en el mundo de la representación del sentido (de la

5 Van Peursen (1968) considera que, en la fenomenología de Husserl, la subjetividad no va más allá de ser pensada desde una perspectiva funcional del conocer, es decir, que en la indagación por el proceso del conocimiento se distingue entre el yo concreto y el yo consciente. Esta distinción se materializa cuando Husserl entra a examinar el problema del tiempo. Efectivamente, la conciencia del tiempo no se da a partir del yo concreto. Entre los dos sujetos, la conciencia objetiva del tiempo se conquista mediante una puesta entre paréntesis del primero, es decir de una reducción trascendental del yo concreto, que deja al yo consciente en una reflexión pura del tiempo mismo (temporalidad). El resultado de esta reducción es un proceso de conocimiento fruto del ego trascendental, o como lo denomina van Peursen, un ego que se entiende como "[...] una operación subjetiva y anónima, que implica su manifestación en la identificación objetiva del tiempo" (Peursen, 1968, p. 178). Para Peursen, la definición inmanente del tiempo subjetivo es propiamente una invención de la fenomenología ontológica de Heidegger, que se distancia de la investigación fenomenológica de Husserl, la cual, sigue el problema desde el horizonte trascendental. 
intencionalidad) y no en el de la experimentación (de la impresionalidad) (Henry, 2009, p. 69). La indigencia ontológica (expresión que acuña Henry para referirse a la ausencia de "carne afectiva" que permea a la teoría de la impresión desde la fenomenología de la intencionalidad), que es la experiencia originaria del tiempo, se desvanece en el ahora de la temporalidad. Para cada experiencia impresiva, que es la misma conciencia del tiempo presente, hay una secuencia, un tiempo en el calendario, pero no un acto originario donde se descubra la subjetividad a sí misma (cf. Henry, 2009, pp. 77-78). El último registro de aquello que ha calado en el fondo de nuestro corazón se desvanece en el pozo profundo del inconsciente. Y en la inercia, en el no Husserl, ser, en la caída, no hay nada...sin embargo Henry percibe en aquella oscuridad del no ser la matriz genuina de la vida (Henry, 2009, p. 70). Efectivamente, mientras que la conciencia del tiempo permanece atrapada en las modalidades clásicas de la temporalidad (antes, ahora y futuro), lo que no cambia, en la impresión misma es la vida a la cual remite toda impresión del dolor y del gozo, en cuanto hace patente no el dato material de la conciencia del tiempo, sino la manifestación absoluta de la experiencia de sí de la vida:

Así, la vida es variable, como el Euripo, de tal modo sin embargo que a través de sus variaciones no cesa de ser la Vida, y ello en un sentido absoluto: es la misma Vida, la misma experiencia de sí que no cesa de experimentarse a sí misma, de ser-absolutamente la misma, un solo y mismo Sí mismo. Cuando decimos que la vida cambia, que este Sí mismo se transforma; queremos decir: lo que experimenta esta experiencia de sí se modifica pero en esta modificación ella no cesa de experimentarse a sí misma, y es justamente ahí, en el cambio lo que no cambia ¿Qué es lo que no se modifica en la vida impresional, la cual no cesa de sufrir nuevas impresiones, de suerte que siempre vuelve de nuevo una nueva impresión? Aparentemente, que la nueva impresión que viene es y será ella también una impresión. Lo que se requiere para su venida es lo que está siempre ya ahí ante ella, y que permanece tras ella, no la forma vacía de un yo pienso o la mirada extática de lo por venir, sino la auto-afección radical de la vida en su efectividad fenomenológica y respecto a la cual toda «nueva impresión» no es sino una modalización. En lo que atañe a nuestra vida no hay, no hay nunca ahora absoluto alguno, que recaería enseguida en el pasado, sino solo esta vida siempre cambiante y siempre la misma. De este modo, no somos ese polichinela que tendría un pie en el ser y otro en la nada. (Henry, 2009, p. 89) 
La relación entre temporalidad e impresión en el Husserl de las Lecciones de 1905 deja a la materia como el último reducto de la oscuridad y del no ser que no puede ser apresado plenamente por una conciencia intencional, si no es a partir de un relato que orienta las experiencias en el antes, el ahora y el futuro. En contraste, en la fenomenología de Henry la impresión emerge de la vida, que edifica la experiencia, y la acrecienta en el devenir que caracteriza al mundo de la vida, Esta no se entiende como el caos de la multiplicidad, sino como el ensanchamiento, el enriquecimiento, la auténtica emancipación de la vida. Las nuevas impresiones que se desatan en el remolino que produce el flujo de las aguas en el río heraclíteo (el mundo de la vida que definió Husserl en Krisis) consolidan la experiencia, y con esto, la autoafección de la subjetividad. Nuevas variables identifican a esta vida que se autoimpresiona, y se resiste a la determinación de un tiempo que vendrá, y es la fuerza, la pulsión, la lucha, el cuerpo. El soma que se experimenta a sí mismo es el sentimiento embriagado, de tal manera que en su intensidad la conciencia y el pathos de la vida se identifican. La conciencia no es conciencia de algo sino pulsión que se arroja plena y absolutamente al poder ciego de la vida (Henry, 2009, pp. 90-92). Las leyes que rigen a la fenomenología material no provienen de la conciencia intencional, sino de la vida misma, una tierra inexplorada para la fenomenología. 


\section{Referencias}

Banfi, A. (1968). Husserl y la crisis de la civilización europea. En Husserl. Tercer coloquio Filosófico de Royaumont (pp. 355-368). Buenos Aires: Paidós.

Cardona Suárez, L. (2002). Inversión de los principios. La relación entre libertad y mal en Schelling. Bogotá: Comares Granada/ PUJ.

Henry, M. (2002). Genealogía del psicoanálisis. El comienzo perdido. Madrid: Ediciones síntesis.

Henry, M. (2009). Fenomenología material. Madrid: Ediciones encuentro.

Husserl, E. (1981). La filosofía en la crisis de la humanidad europea. En La filosofía como ciencia estricta. Buenos Aires: Nova.

Husserl, E. (2008). La crisis de las ciencias europeas y la fenomenología trascendental (Julia Iribarne, trad.). Buenos Aires: Prometeo libros.

Ricœur, Paul. (2009). Freud, una interpretación de la cultura. Siglo XXI editores.

Mussil, Robert. (2006). Diarios. Bogotá: Random house Mondadori.

Safranski, R. (2010). El mal o el drama de la libertad. Barcelona: Tusquets Editores.

Schelling, F. W. J. (1989). Investigaciones filosóficas sobre la esencia de la libertad humana y los objetos con ella relacionados. Barcelona: Anthropos.

Van Peursen, C. A. (1968). La noción de tiempo y de ego trascendental en Husserl. En Husserl. Tercer coloquio filosófico de Royaumont (pp. 175-185). Buenos Aires: Paidós. 